\title{
Analysis of the Cutting Fluid Influence on the Deep Grinding Process with a CBN Grinding Wheel
}

\author{
Ronaldo Yoshinobu Fusse ${ }^{\text {a }}$, Thiago Valle França ${ }^{a}$, Rodrigo Eduardo Catai ${ }^{\text {, }}$ \\ Leonardo Roberto da Silva ${ }^{\mathrm{c}}$, Paulo Roberto de Aguiar ${ }^{\mathrm{d}}$, Eduardo Carlos Bianchi ${ }^{\mathrm{e} *}$ \\ ${ }^{\mathrm{a}}$ Graduate Students - Paulista State University - UNESP, \\ Department of Mechanical Engineering, 17033-360 Bauru - SP, Brazil \\ ${ }^{\mathrm{b}}$ Dr. Mechanical Engineering - Paulista State University - UNESP, \\ Department of Materials and Technology, Guaratinguetá - SP, Brazil \\ ${ }^{\mathrm{c}}$ Prof. Dr. Department of Mechanical, Federal Center of Technological Education-CEFET, \\ Belo Horizonte - MG, Brazil \\ ${ }^{\mathrm{d}}$ Prof. Dr. Department of Electric Engineering, UNESP, Bauru - SP, Brazil \\ ${ }^{\mathrm{e}}$ Prof. Dr. Department of Mechanical Engineering, UNESP, Bauru - SP, Brazil
}

Received: November 21, 2003; Revised: May 3, 2004

\begin{abstract}
The application of cutting fluid in a deep grinding process is becoming more and more important, mainly where the cutting fluids are used as an "external" agent to the grinding conditions. The role of the fluid in grinding operations is in refrigeration of the workpiece, removal of the shavings, lubrication of the grinding zone, and refrigeration and cleaning of the wheel. The efficiency of a cutting fluid will depend mainly of the type of fluid that will be used. In this work, the influences of the type of cutting fluid used in a deep grinding process of the steel VC131 using CBN grinding wheel are analyzed. Three different types of cutting fluids were used: a vegetable emulsion, a synthetic solution and a integral oil. The variables analyzed during and after the grinding process were the grinding force, the superficial roughness, the acoustic emission (EA), the temperature of the piece and the $\mathrm{G}$ ratio (relationship between the volume of material removed from the piece and the volume worn off the grinding wheel). The integral oil showed the best performance relative to the following output variables: EA, cutting force and $\mathrm{G}$ ratio. The vegetal emulsion was the fluid that best dissipated heat from the cutting region.
\end{abstract}

Keywords: machining, grinding, CBN wheel, cutting fluid.

\section{Introduction}

Grinding is a machining process employed for the attainment of tight tolerance (two-dimension tolerance between IT4 e IT6 and compatible geometric tolerance) and reduced roughness values (Ra from 0.2 to $1.6 \mu \mathrm{m})^{2}$. Due to the great number of variables involved, grinding is one of the most complex machining processes.

The search for increased productivity and quality in recent years has led to great advancements in machining processes. Such advancements occur at the conventional operations as well as at the simplification of a component manufacturing sequence with the exchange from intermediate operations to finishing operations.

In the plunge grinding process, the workpiece is fixed upon a magnetic plate, which remains held on the grinding machine's table. The workpiece has a pendulous longitudinal movement with velocity $\mathrm{v}_{\mathrm{w}}$. The grinding wheel with outer diameter $\mathrm{ds}$ $(\mathrm{mm})$, has cutting velocity vs, and penetrates into the workpiece with depth (a), (schematically) shown by Fig. 1.

According to Webster \& $\mathrm{Ciu}^{10}$, the employment of fluids in machining processes is becoming even more important due to higher removal rates and improved, longer- lasting grinding wheels. Furthermore, proper fluid employment at the cutting zone may be as important as the grinding wheel specification choice.

The cutting fluids are employed as an "outer agent" to the machining conditions. The roles the fluids play at the machining operations are: to refrigerate the workpieces, to remove the chips, to lubricate the machining zone, to re- 
frigerate and to clean the grinding wheel, among others. A great variety of oils and cutting fluids are available in the market for the different machining processes, and the choice might be influenced by factors such as viscosity, technical features, and cost among others.

This paper has as its main purpose to analyze the influence of the type of cutting fluid employed in the grinding operation with high depth of cut (depth of cut "a" of $70 \mu \mathrm{m}$ ), with CBN (Cubic Boron Nitride) superabrasive grinding wheel manufactured with vitrified bond.

In this work, the type of material to be ground, the fluid pressure and flow rate, the machining condition and the grinding wheel will be fixed. Only the cutting fluids will vary. In this way we will attempt to verify the influence of some types of cutting fluids on the cutting tangential force behavior, on the workpiece superficial roughness, on the acoustic emission (EA), on the temperature and on $\mathrm{G}$ ratio (relation between the volume of material removed from the piece and the volume worn off the grinding wheel).

\section{Bibliographical Review}

\subsection{Cutting fluid}

\subsubsection{Classification of cutting fluid}

Each basic type of cutting fluid shows features, advan-

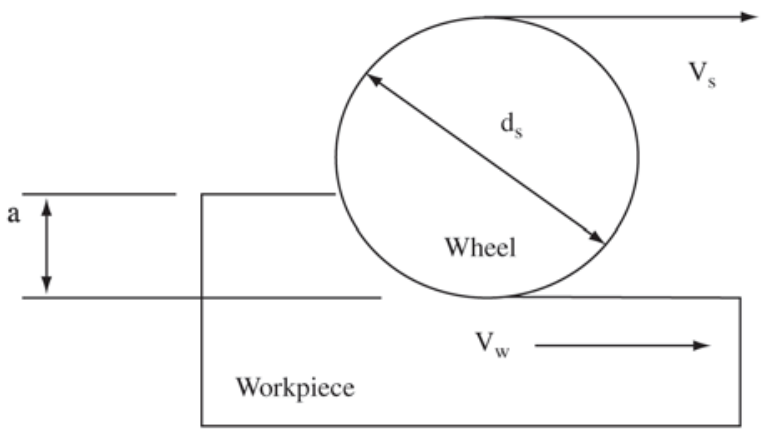

Figure 1. This figure shows the plunge grinding process. tages and specific limitations. However, the features that distinguish the different classes are not always easily seen, with small differences according to their classification ${ }^{5}$. According to Runge \& Duarte ${ }^{6}$ and $\mathrm{ASM}^{1}$, the cutting fluids may be grouped into four basic types:

- cutting oils (integral oil or emulsified);

- water-soluble cutting fluids:

- conventional emulsifiable;

- semi-synthetic emulsifiable;

- solutions (synthetic fluids);

- gases and pastes.

\subsubsection{Functions of a cutting fluid in the grinding process}

In order to be effective, the cutting fluid should not only provide good workpiece cooling by convection, but it should perform well at the chip formation mechanism, furthering the cut (chip formation) instead of producing plastic deformation with no material removal (plowing). As result, there is a reduction on the required grinding specific energy for the machining process ${ }^{4}$.

Table 1 shows some characteristics of the most common cutting fluids for machining processes in industries. According to Diniz et al. ${ }^{2}$, water-base fluids have two meaningful disadvantages: low lubricating content and easier promotion of oxidation in workpieces and machine. However, the integrals oils seem to provide better lubricating power than the water-base fluids (solutions and emulsions).

\section{Materials and methods}

\subsection{Types of employed cutting fluids}

Three types of fluids will be employed: a vegetal emulsion, a synthetic solution and integral oil. The outlines of each type of fluid are below.

CutMaxCF 10: Integral oil free from chlorine. Its basic contents are: paraffin mineral oil, grease, extreme-pressure additive and anti-oxidizer.

Hocut 4110: Synthetic cutting fluid solution formative.

Hocut 2010: Water-soluble cutting fluid, biologically decomposed, vegetal emulsion formative, of which the basic contents are: vegetal oil free from mineral oil, nitrites,

Table 1. Characteristics of the most important fluid types (Webster, 1995).

\begin{tabular}{lcccc}
\hline & Synthetic & Semi-Synthetic & Soluble Oil & Mineral Oil \\
\hline Heat removal & Excellent & Outstanding & Good & Bad \\
Lubrication & Bad & Good & Outstanding & Excellent \\
Maintenance & Outstanding & Good & Bad & Excellent \\
Filterability & Excellent & Outstanding & Good & Bad \\
Environmental & damages & Excellent & Outstanding & Good Bad \\
Cost & Excellent & Outstanding & Good & Bad \\
\hline
\end{tabular}


heavy metals and phenolic compounds.

The water-soluble cutting fluids were prepared at $5 \%$ concentration and the $\mathrm{pH}$ measurement was performed before the beginning of each test All cutting fluids showed $\mathrm{pH}$ levels between 7.2 and 10.8 .

\subsection{Type of employed grinding wheel}

A CBN B76R125V12 superabrasive grinding wheel, with $350 \mathrm{~mm}$ diameter and $20 \mathrm{~mm}$ width vitrified bond was employed. The truing operation was performed through a truing device fixed to the machine's table, placed at the horizontal position underneath the grinding wheel, lined up with its gravity center. As the grinding wheel runs, a transversal rectilinear movement was performed relative to the grinding wheel, in order to remove the toll's irregular layer, this way generating new cutting corners for each proposed test performance.

\subsection{Workpieces}

The samples were manufactured with VC 131 tempered steel and re-tempered with hardness of approximately 60 HRC. The samples approximate dimensions were $200 \mathrm{~mm}$ length, $20 \mathrm{~mm}$ height and $5 \mathrm{~mm}$ thickness. Three holes of $2 \mathrm{~mm}$ diameter by $5 \mathrm{~mm}$ away from one another were made, in order to fix the thermocouple.

\subsection{Machining conditions}

- Machining conditions fixed for the tests include:

- Fluid flow rate = 10 1/min;

- Grinding wheel velocity $=\mathrm{V}_{\mathrm{s}}=65 \mathrm{~m} / \mathrm{s}$;

- Table velocity $=\mathrm{V}_{\mathrm{w}}=0.04 \mathrm{~m} / \mathrm{s}$;

- Optimized nozzle with fluid output diameter $=8 \mathrm{~mm}$;

- "a" is the cut depth $=70 \mu \mathrm{m}$;

- $\mathrm{h}_{\mathrm{eq}}$ is the cut equivalent thickness $=0.1 \mu \mathrm{m}$.

Initially the workpiece was fixed on the grinding machine's table according to Fig. 2 and afterwards all machin-

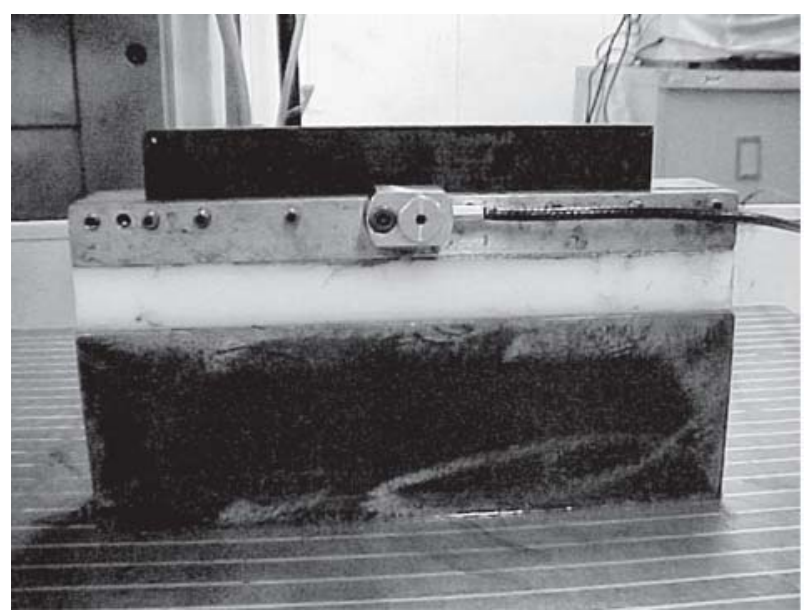

Figure 2. Fixing the workpiece on the plane grinding table. ing conditions (cutting velocity, table velocity and grinding wheel's penetration into the workpiece) were set.

The tests were then conducted, measuring the cutting force, EA and the temperature in real time. The grinding wheel diametric wear was marked on a workpiece at the end of each test and the roughness measured each 25 moves of the grinding wheel.

\subsection{Thermocouples fixed to the workpiece}

The thermocouples were fixed to the workpiece with instantaneous glue; only the tips were glued to the workpiece. The thermocouple tips were attached through a solder performed with acetylene flame.

The thermocouples were connected to the A/D plate, where it was possible to monitor temperature in real time through a digital display.

\subsection{Acoustic emission sensor}

For the acquisition of the acoustic emission in real time, using the equipment Sensis Manufacturer, model BM12 was employed, and the sensor was fixed next to the piece case.

\subsection{Superficial roughness measurement}

The superficial roughness of the parameter workpiece $\mathrm{R}_{\mathrm{a}}$, was taken each 25 grinding wheel moves, employing a roughness measurement instrument of TAYLOR HOBSON, model Surtronic $3+$. The measurements were performed at three different positions from the workpiece (sides and center) and three successive times at each position. The amount of material removed was $25 \mu \mathrm{m}$.

\subsection{Measurement of $G$ ratio}

At the end of each test, the grinding wheel was marked on a workpiece, which was fixed to the grinding table, in such way to remain perpendicular to the grinding wheel's face. With the aid of an electronic displacement measurer TESA; model TT10, with accuracy of $1 \mathrm{~mm}$, three measurements at the grinding wheel wear and at the sides regions were performed. G ratio, which expresses the grinding wheel performance, was obtained through the division of the removed material volume by the volume of the worn grinding wheel.

\subsection{Cutting tangential force}

For the cutting tangential force, the measurement at real time was performed through the grinding wheel rotation $n$ and the electric power $\mathrm{P}_{\mathrm{c}}$ spent by the actuation motor of the abrasive tool, during cut. In that purpose, a signals conditioning circuit was employed, which allows the acquisition and the transformation of values from the electric current, electric tension and motor rotation into signals of compatible electric tension, to be sent to a data acquisition system (A/D board). Using LabVIEW data acquisition soft- 
ware, previously determined calibration equations as well as the tension values were read from the data acquisition plate, then the cutting tangential force $\mathrm{Ft}_{\mathrm{c}}$ was calculated using Eq. 1, with $\mathrm{d}_{\mathrm{s}}$ as the grinding wheel diameter:

$$
\mathrm{Ft}_{\mathrm{c}}=60 \times \mathrm{P}_{\mathrm{c}} /\left(2 \times 3.1415 \times \mathrm{n} \times \mathrm{d}_{\mathrm{s}}\right)
$$

\subsection{Initial parameters}

\subsubsection{Type of nozzle to be employed}

An optimized nib with an $8 \mathrm{~mm}$ diameter nozzle was employed, as shown by Fig. 3, in order to show a better flow rate-pressure set.

\section{Results and Discussion}

For each of the tested fluids, results were obtained for the following output variables: roughness, cutting tangential force, acoustic emission, temperature and $\mathrm{G}$ ratio.

For the cutting force and EA, an average was calculated for each grinding wheel move. Two points expressing the beginning and the end of the workpiece grinding were selected. The choice of the points was made manually, since the data acquisition was made only toward the table displacement (incompatible movement between workpiece and grinding wheel), and the acquired data would not happen at equal time intervals. When the table retook on the opposite movement, the computer program was stopped and an advancement of $70 \mathrm{~mm}$ was made for a new grinding wheel move.

\subsection{Results for the average superficial roughness}

The roughness was obtained after 25 grinding wheel moves, where three measurements at the border and at the middle of the workpiece were performed. Then, the roughness average along the workpiece as a function of the number of moves was calculated. The Fig. 4 shows roughness for the tested fluids.

Analyzing the soluble fluids HC 2010 (vegetal emulsion), HC 4110 (synthetic solution), one observes that both have similar behavior with relation to the roughness $\left(\mathrm{R}_{\mathrm{a}}\right)$, without significant differences. All that, in function of the non-em-

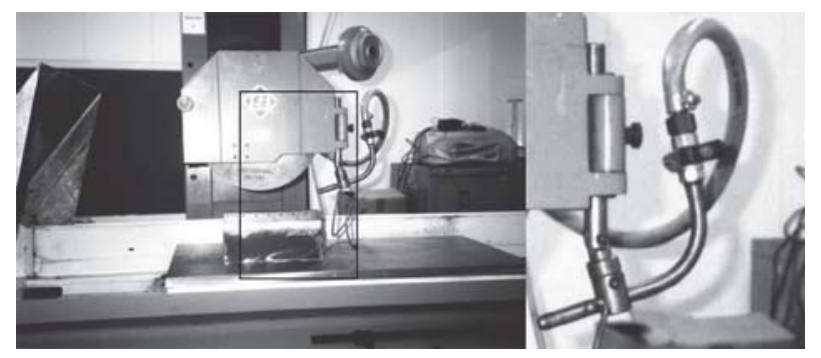

Figure 3. Nozzle used. ployment of the unitary relation (where the fluid employment velocity is equal to the grinding wheel peripheral velocity) due to the technical limitations, the pressure and flow rate requirements. For these cases, it was not possible to overcome effectively the air barrier brought by the grinding wheel rotation, which could be replaced by adopting the unitary relation between the velocities, as observed by Webster (1995, 1999), for a correct application of the fluids.

For the integral oil, a higher roughness $\left(\mathrm{R}_{\mathrm{a}}\right)$ was obtained in relation to other fluids, due to the fact that its highest viscosity requires an employment minimum flow rate, in order to guarantee adequate lubrication. According to Webster (1999), there is a critical flow rate, which can be defined as a determinate jet output velocity, where above this value, the final properties of the ground workpieces might be improved.

Therefore, the fluids that showed the lowest roughness were the water soluble ones: vegetal emulsion and synthetic solution.

\subsection{Results for the acoustic emission}

According to Soares \& Oliveira (2002), the acoustic emission (EA) is characterized by tension waves produced by the sudden movement of the tensioned materials, and the classical emissions come from deformation processes, such as cracking and plastic deformations. Those sudden movements generate tensions, which diffuse through the material by physical environments, until it reaches the EA sensor, and the most employed nozzle for the sensors fixing are the counterpoint, the cube or the grinding wheel axis, or even the cutting fluid tube. This is the most effective value acquisition method; the sensor receives electric signals of high frequency and remains free from noises from sources external to the process.

Analyzing Fig. 5, which shows the comparison of the acoustic emission values for the tested fluids, one observes that the integral oil was the fluid showing the highest values and the greatest temperature variation for acoustic emission due to the fact that its highest viscosity requires an

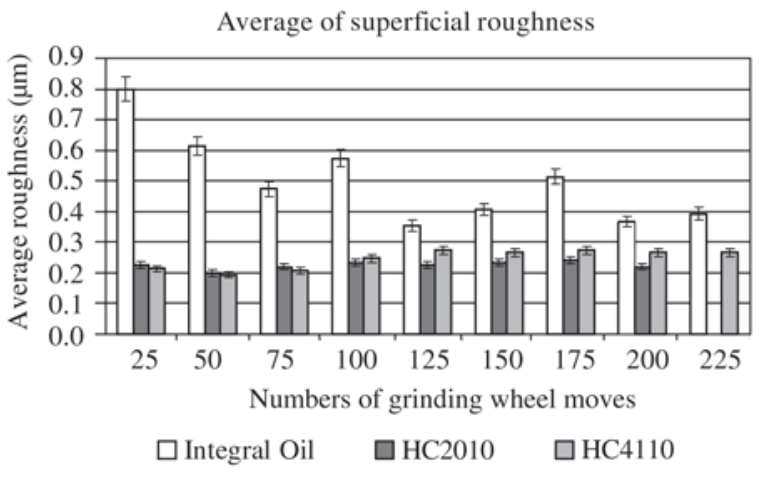

Figure 4. Comparative results for the average roughness. 
employment minimum flow rate, in order to guarantee adequate lubrication. Analyzing the vegetal emulsion and synthetic solution, one observes that both have similar behavior with relation to the acoustic emission, without significant differences. All that, in function of the non-employment of the unitary relation.

\subsection{Results for the cutting tangential force}

The Fig. 6 shows the comparison of the obtained values for the cutting tangential force.

The soluble fluids produced cutting force values less stable than the integral oil. The vegetal emulsion initialized with greater cutting force, but was more stable than the synthetic solution over the course of the trial. The synthetic solution showed more instability during the process.

The integral oil showed more stable behavior for the

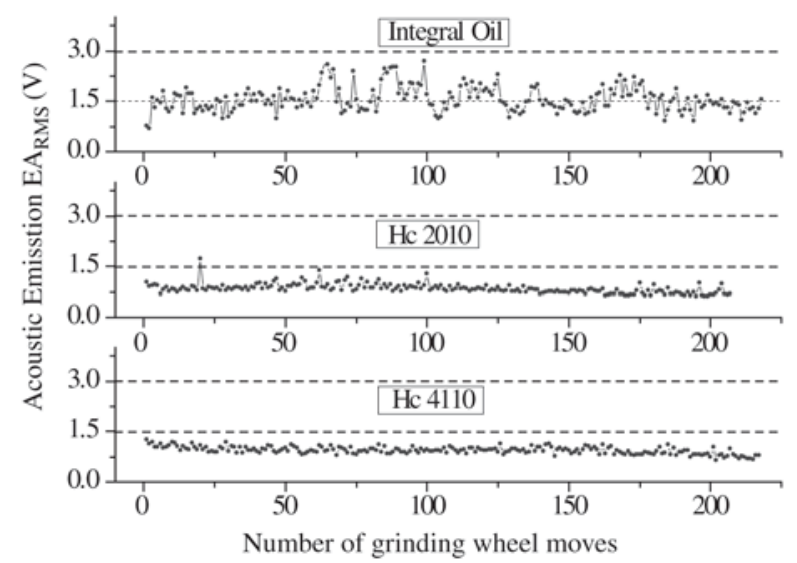

Figure 5. EA comparative results for the fluids.

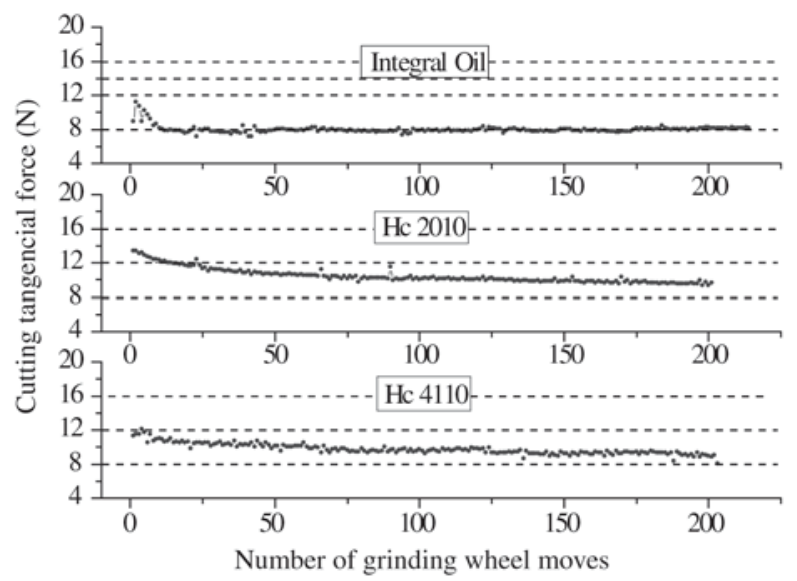

Figure 6. Tangential force comparative results. cutting force, as the number of moves increased, when compared to the other tested fluids. It also showed a lower cutting value throughout the entire process. This is explained by the higher lubricating capacity of this integral oil compared to the others tested. The integral oil turns the grinding wheel sharper, inhibiting the precocious wear of abrasive grains, through the decrease of the grain-workpiece friction coefficient. In this way, it allows a smoother cut, reducing the dissipated energy, once the cut is facilitated (Hitchiner, 1990).

\subsection{Results for the temperature}

Figures 7, 8, 9 show the temperatures for the three employed thermocouples.

The breaching of the first thermocouple happened approximately at the $70^{\text {th }}$ move after the grinding of $5 \mathrm{~mm}$ from the material. The $2^{\text {nd }}$ thermocouple breached at the $140^{\text {th }}$ grinding wheel move and the $3^{\text {rd }}$ at the $210^{\text {th }}$ move,

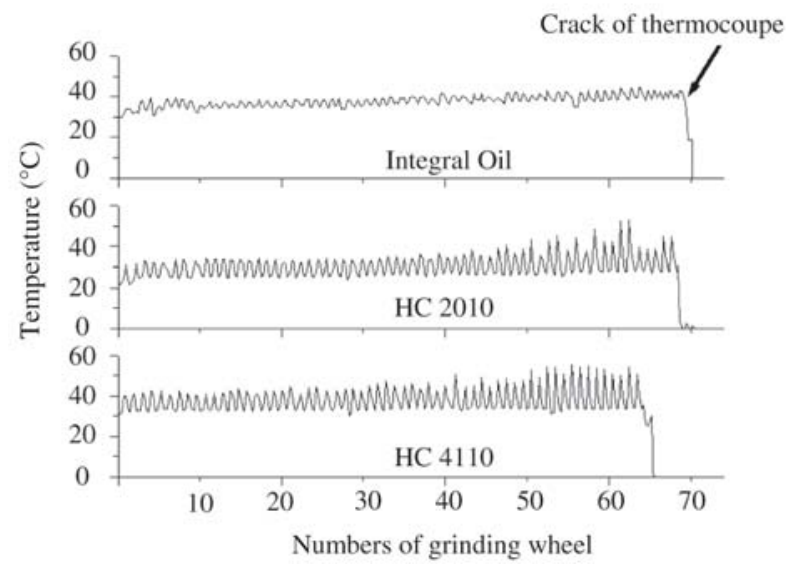

Figure 7. Comparative results of temperatures for the $1^{\text {st }}$ thermocouple.

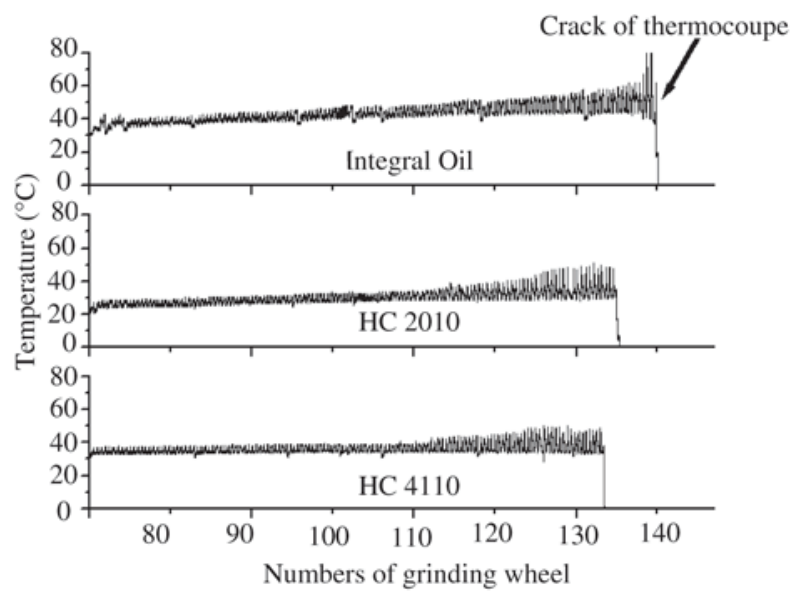

Figure 8. Comparative results of temperatures for the $2^{\text {nd }}$ thermocouple. 
both after the grinding of $5 \mathrm{~mm}$ from the workpiece. This breaching may be seen at all thermocouples every time there is a sudden temperature drop.

Similar breaching behavior when cutting fluids are changed is also observed, once as it gets next to the thermocouple breaching (after $5 \mathrm{~mm}$ of removed material), the temperature starts to increase and just when the thermocouple breaches, there is a sudden temperature drop.

The integral oil has presented higher values of temperatures for all three thermocouples due to its low specific heat, which shows its low efficiency at heat dissipation.

The vegetal emulsion, which is a composite of vegetal oil without mineral oil, nitrite, heavy metals and phenolic compounds, has presented lower values of temperatures with regard to the synthetic solution (oil diluted in water) for all thermocouples due to the moisture characteristics, that is, the vegetal emulsion has no oil and thus its cooling capacity is high which turns out lower values of temperatures. So, it can be concluded that the vegetal emulsion has presented the best performance in heat dissipation.

\subsection{Results for the $G$ ratio}

The Fig. 10 shows the comparison of $\mathrm{G}$ ratio values for the tested cutting fluids.

The highest values for $\mathrm{G}$ ratio were obtained for the integral oil. That may be explained by the higher lubricating capacity of this fluid, when compared to the other tested fluids. Those results were also observed by Carius (1989) apud Webster ${ }^{8}$, where, in most cases, the grinding wheel radial wear is reduced by the integral oil employment. The vegetal emulsion and the synthetic solution showed similar behavior with relation to the grinding wheel radial wear; however, little difference between these fluids can be verified with significant differences. The vegetal emulsion showed higher $\mathrm{G}$ ratio than the synthetic solution, in other words, a smaller value of the grinding wheel radial wear in function of the non-employment of the unitary relation for a correct application of the fluids.

\section{Conclusions}

Analysis of the results obtained for the plane grinding process with high cutting depth, "a", by machining cycle (grinding wheel move cutting on the workpiece), yields these conclusions:

Among the tested cutting fluids, the integral oil showed the best performance with relation to the following output variables: cutting tangential force and $\mathrm{G}$ ratio, mainly due to its great lubricating power. The vegetal emulsion was the cutting fluid that best dissipated heat from the cutting region, proving its great cooling power. Concerning the superficial roughness, the vegetal emulsion and the synthetic solution showed similar behavior and both better

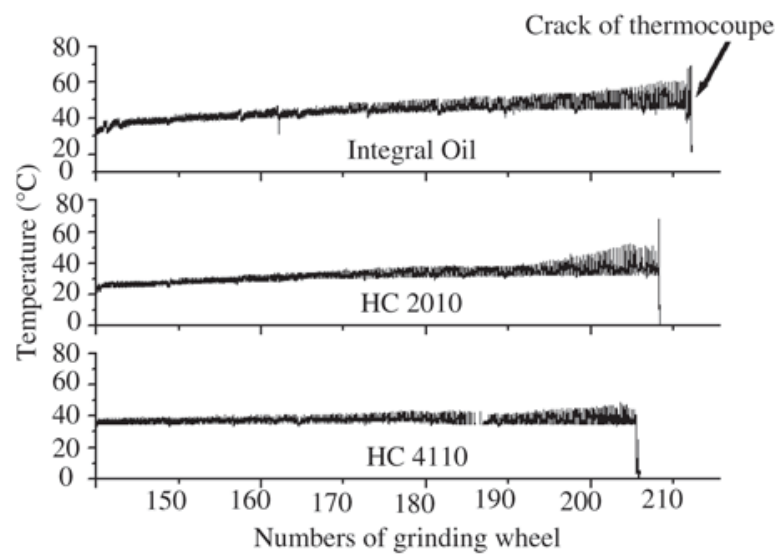

Figure 9. Comparative results of temperatures for the $3^{\text {rd }}$ thermocouple.

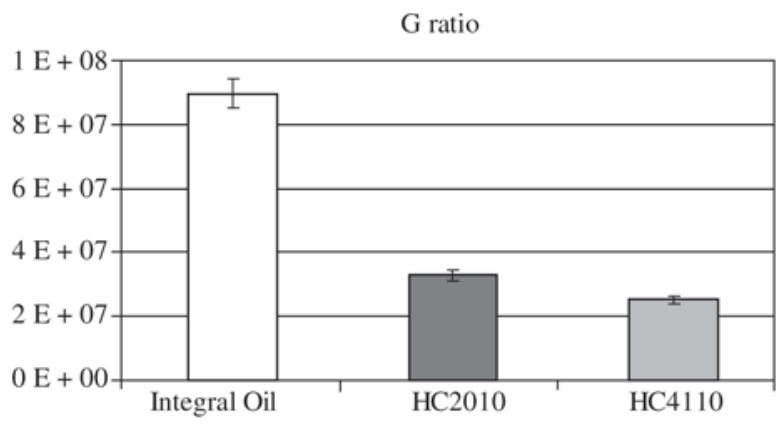

Figure 10. Comparative results for $\mathrm{G}$ ratio.

than the integral oil. However, according to Webster (1995), the roughness and the acoustic emission can be reduced for the integral oil, by increasing the velocity and the fluid pressure at the cutting region. However, in this study technical limitations prevented us from testing this theory. It is important to highlight that the $\mathrm{G}$ ratio in the tested fluids was high, due to the small wear of the CBN grinding wheel with relation to the volume of the removed material.

\section{References}

1. ASM International Handbook Committee, Metals Handbook, ed. 6, cap. 27, p. 14-20, May, 1991.

2. Diniz, A.E.; Marcondes, F.C.; Coppini, N.L. Technology of the machining of the materials, Second Edition, Artiliber Publisher Limited, p. 165, Campinas, Brasil, 2000.

3. Hitchiner, M.P. Precision Grinding Systems for Production Grinding with Vitrified CBN, SME Technical Paper MR90-507, p. 1-11, 1990. 
4. Malkin, S. Grinding Mechanisms e Grinding Temperatures and Thermal Damage, In: MALKIN, S., Grinding Technology: theory and applications of machining with abrasives, Chichester, Ellis Horwood Limited, cap. 5 e 6, ed. 1, p. 108-171, 1989.

5. Motta, M.F., Machado, A.R. Fluidos de corte: tipos, funções, seleção, métodos de aplicação e manutenção, Revista Máquinas e Metais, Setembro, p. 44-56, 1995.

6. Runge, P.R.F., Duarte, G.N. Lubrificantes nas indústrias Produção, manutenção e controle Triboconcept Edições Técnicas, p. 71-171, 1990.

7. Soares, D.D., Oliveira, J.F.G. Diagnóstico do processo de retificação pela análise dos sinais, Revista Máquinas e Metais, Ano XXXVIII, n. 436, p. 140-157, Maio, 2002.

8. Webster, J. Selection of coolant type and application technique in grinding, Supergrind, p. 205-218, 1995.

9. Webster, J. Optimizing coolant application systems for high producing grinding, Abrasives Magazine, p. 34-41 Oct. /Nov., 1999.

10. Webster, J.; CIU, C. Flow Rate and Jet Velocity Determination for Design of a Grinding Cooling System, Presented at 1st International Machining e Grinding conference, Dearborn, p.12-14, MI, September, 1995. 